\title{
Fe Supported Alumina Catalyst for Methane Decomposition: Effect of Co Coupling
}

\author{
Anis H. Fakeeha ${ }^{a}{ }^{*}$, Ahmed A. Ibrahim ${ }^{a}$, Ahmed S. Al Fatesh ${ }^{a}$, Wasim U. Khan ${ }^{a}$, \\ Yahya A. Mohammed ${ }^{a}$, Ahmed E. Abasaeed ${ }^{a}$, Mostafa A. Soliman ${ }^{b}$ and Raja L. Al-Otaibi ${ }^{c}$ \\ ${ }^{a}$ Chemical Engineering Department, College of Engineering, King Saud University, Riyadh, Saudi Arabia \\ ${ }^{b}$ Chemical Engineering Department, British University in Egypt, El Sherouk City, Cairo, Egypt \\ ${ }^{c}$ King A City for Science and Technology (KACST), Saudi Arabia
}

\begin{abstract}
In recent years hydrogen production received enormous attention, since it is an environmentally friendly, energy source. The aim of this research was to examine the hydrogen production with the help of methane's catalytic decomposition. $30 \%$ Fe coupled with different $\%$ of Co over alumina support, were examined by catalytic decomposition of methane for the production of hydrogen. The catalysts were prepared by impregnation method. The catalytic activity results revealed that the catalysts, coupled $15 \%$ Co gave the highest conversion of $72.5 \%$ as depicted by the three hour time on stream profile. The fresh and spent catalysts were characterized using different techniques such as BET, $\mathrm{H}_{2}$-TPR, and XRD.
\end{abstract}

Keywords: $\mathrm{Al}_{2} \mathrm{O}_{3}$, Carbon Nanotubes, $\mathrm{Co}, \mathrm{Fe}$, Hydrogen, Methane

\section{Introduction}

Nowadays, hydrogen is regarded as ideal fuel that can replace the fossil, particularly when it is produced without carbon oxides. Hydrogen can easily be used not only directly as a clean and valuable fuel for heating, industrial processes and automobile, but also as a storable energy carrier as it can be transported economically as well as efficiently over extensive distances. Hence, hydrogen is being looked upon as an ideal energy carrier. Hydrogen production processes are many, for instance, steam, $\mathrm{CO}_{2}$ reforming of methane, reforming of biomass, partial oxidation of natural gas, coal gasification and water photolysis [1-7]. The main disadvantage of these processes is the combination of $\mathrm{CO}$ and $\mathrm{CO}_{2}$ gases with $\mathrm{H}_{2}$ gas production [9]. Thus, it is necessary to perform the separation of carbon oxides to avoid the rapid catalyst deactivation due to the use of impure hydrogen and therefore the cost of hydrogen production rises [10]. Consequently, hydrogen formation via catalytic decomposition of methane (CDM) was found as a potential process for COx-free hydrogen production [11,12]. Furthermore, the CDM process is associated with the coproduction of valuable nano carbon materials such as multiwalled carbon nanotubes, which possess superb properties that rends them useful for a variety of applications [13]. Conversion of methane depends upon the catalyst matrix which comprises the active material and the support [14]. Transition metals of Group VIII such as $\mathrm{Ni}, \mathrm{Co}$ and Fe have been widely employed in CDM at moderate conditions [15,16].. Pradhan et al[17] have utilized Fenton Chemistry to degrade PNP using $\mathrm{Fe}^{+2} / \mathrm{H}_{2} \mathrm{O}_{2}$ along with $\mathrm{HC}$ to great effect, achieving maximum PNP removal of $63.2 \%$. The following work attempts to build upon this synergism between $\mathrm{HC}$ and $\mathrm{H}_{2} \mathrm{O}_{2}$ to achieve higher PNP degradation extents.

${ }^{*}$ Corresponding author

Email: anishf@ksu.edu.sa

(C) 2015 International Association for Sharing Knowledge and Sustainability

DOI: $10.5383 /$ swes.7.01.006 


\section{Experimental}

\section{Catalyst Performance Evaluation}

Catalytic methane decomposition experiments over $\mathrm{Fe}$ based catalysts were performed at atmospheric pressure within the vertical stainless steel fixed-bed tubular (9.1 $\mathrm{mm}$ i.d. and $30 \mathrm{~cm}$ long) micro-reactor (PID Eng \& Tech micro activity reference). $30 \% \mathrm{Fe} / \mathrm{Al}_{2} \mathrm{O}_{3}$ e was coupled with various loadings of cobalt $(0 \%, 6 \%, 15 \%$ and $30 \%)$. The reaction setup used in this study was shown in Figure 1. The setup comprised three major segments: feed gas delivery, catalytic reactor, and products analysis section. The feed section contained two gas cylinders of $\mathrm{CH}_{4}$ and $\mathrm{N}_{2}$. All gases were of high purity and purchased from local suppliers. Reactant gases coming from the regulators were passed through in-line filters, and then introduced to the mass flow controllers (MFC). The gases after mixing are fed to the reaction section. Online samples of the feed gas mixture were directed through a sampling valve to the gas chromatograph (GC) for analysis.

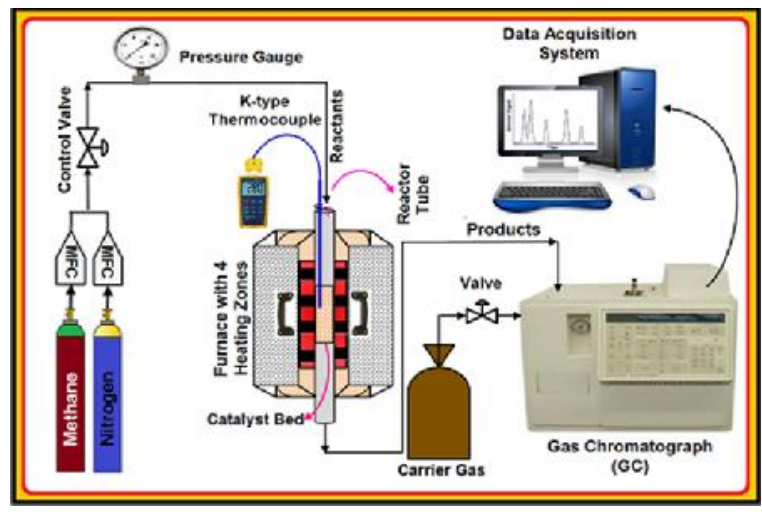

Fig. 1 Schematic Diagram of Experimental Setup

A typical activity test was conducted over a fixed mass (0.3 grams) of catalyst, and it was placed over a quartz wool bed. In order to monitor the actual temperature in the reactor, a K-type stainless steel sheathed thermocouple was placed axially at the center of the catalyst bed. After loading the catalyst, a constant flow of $\mathrm{N}_{2}(20 \mathrm{ml} / \mathrm{min})$ was introduced to the reactor, to purge the moisture, air and other gases from the reactor. Before carrying out activity tests, the catalysts were exposed to reduction treatment under a continuous flow of $\mathrm{H}_{2}(40 \mathrm{ml} / \mathrm{min})$ at $500{ }^{\circ} \mathrm{C}$ for $90 \mathrm{~min}$. After reduction, the system was again flushed with $\mathrm{N} 2$ about 20 min to flush out any physisorbed and residual hydrogen from the reactor. Then, the temperature of the reactor was increased to the desirable temperature of the reaction $\left(700{ }^{\circ} \mathrm{C}\right)$ in the presence of $\mathrm{N}_{2}$.
Once the desired temperature was achieved, a feed mixture of pure methane and $\mathrm{N}_{2}$ gas was fed into the reactor to accomplish the methane decomposition. In a typical test, the volume ratio of the feed gas mixture, i.e., methane/nitrogen was 1.5/1; whereas, the accumulative flow rate was found to be 25 $\mathrm{ml} /$ minute, having the space velocity of almost $5000 \mathrm{ml} / \mathrm{h}$.gcat. The composition of the outlet gas was tested online with the help of gas chromatography (Shimadzu GC-2014). It was embedded with thermal conductivity detector using the PP-Q column. Afterwards, the reactor was cooled to room temperature. Subsequently, the cooled catalyst was taken for characterization.

$\mathrm{CH}_{4}$ Conversion was calculated by using the following formulae:

$$
\mathrm{CH}_{4} \text { Conversion }(\%)=\frac{\mathrm{CH}_{4} \text { in }-\mathrm{CH}_{4} \text { out }}{\mathrm{CH}_{4} \text { in }} \times 100
$$

\section{Catalyst Preparation}

Analytical grades of Iron and cobalt nitrates and high activity gamma alumina were employed for the preparation of catalysts using the impregnation methods. In this the active metal precursor i.e. Fe and Co nitrates were added in distilled water and subsequently the alumina support. The mixture was heated at $80^{\circ} \mathrm{C}$ for $3 \mathrm{hr}$ under constant stirring to impregnate the active metal over supports. After that impregnated catalysts were placed in the furnace at the temperature of $120^{\circ} \mathrm{C}$ overnight. It was then followed by the calcination at $450^{\circ} \mathrm{C}$ for $3 \mathrm{~h}$.

\section{Results and Discussion}

In this work, investigation of catalytic decomposition of methane to produce hydrogen and carbon was conducted at $700^{\circ} \mathrm{C}$ reaction temperature using iron based supported catalysts on alumina. The active metal was coupled with different loadings of cobalt. Pure methane and nitrogen were fed to the reactor. The inert gas $\mathrm{N}_{2}$ constituted $10 \%$ of the feed. No appreciable amount of methane decomposed during the test of feed in the absence of catalysts under the similar experimental conditions of temperature and therefore, no hydrogen was detected by gas chromatography. Catalyst activities toward hydrogen production and stability tests and their corresponding characterization results were presented. The textural properties of the catalysts have been extracted from the $\mathrm{N}_{2}$ adsorption-desorption isotherms. Analysis of the isotherms of the prepared catalysts (Fig.2) revealed hysteresis loops of slightly different shaped; however, the observed adsorption-desorption isotherms were similar to type IV. The hysteresis loops were of type $\mathrm{H}_{2}$ shaped. It was also clear that the amount $\mathrm{N}_{2}$ adsorption-desorption increased with the increase of the relative pressure. When the $30 \% \mathrm{Fe} / \mathrm{Al}$ was coupled with $6 \%$ and $15 \%$ Co the amount $\mathrm{N}_{2}$ adsorptiondesorption decreased but it increased when $30 \%$ Co. This was consistent with relative changes of the textural properties of the catalysts and hence the variation of the surface area. 


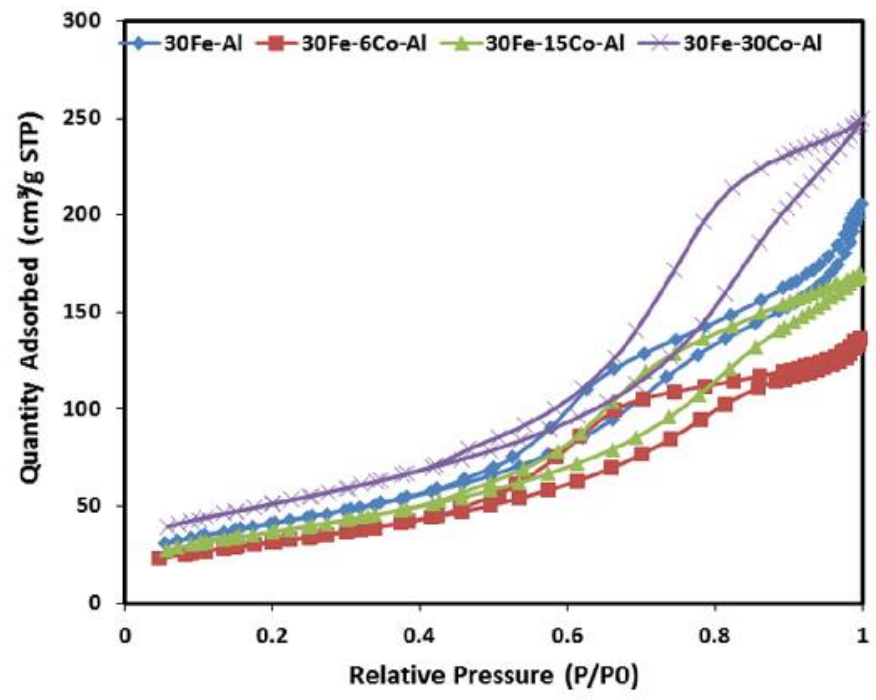

Fig.1 $\mathrm{N}_{2}$ Adsorption-Desorption Isotherms for Fresh 30Fe-xCo/ Al Catalyst Series for Different Loading of Cobalt

To understand the basis of the enhancement in catalytic activity, $\mathrm{H}_{2}$-TPR was performed. Fig. 3 exhibited the $\mathrm{H}_{2}$-TPR profile for alumina supported iron catalyst coupled with loadings of cobalt. TPR patterns for different cobalt loading catalysts are fairly similar to each other specifying that catalysts had undergone similar reduction behavior. The response of cobalt loadings and $30 \% \quad \mathrm{Fe} / \mathrm{Al}_{2} \mathrm{O}_{3}$ temperature scan using hydrogen as reducing agent provides three peaks in the TPR profiles. Indeed, this is a common feature of Fe based catalyst [17]. Their signals appear around 272-462, $409-745,760-902^{\circ} \mathrm{C}$ with peak maximum centered at 385 ,
575 and $843^{\circ} \mathrm{C}$ respectively. These regions of temperature obviously identify that catalytic methane decomposition follows three mechanisms that are predominant at different temperatures. The first peak is attributed to the transformations of $\mathrm{FeOOH} \rightarrow \mathrm{Fe}_{2} \mathrm{O}_{3}$ while the second peak is ascribed to the reduction of $\mathrm{Fe}_{2} \mathrm{O}_{3} \rightarrow \mathrm{Fe}_{3} \mathrm{O}_{4}$, whereas the third peak denotes the transformation of $\mathrm{Fe}_{3} \mathrm{O}_{4} \rightarrow \mathrm{Fe}$ [18]. The increment in the cobalt loading from $6 \%$ to $15 \%$, shifted the reduction peaks to higher temperatures. This could be due to the variation of the extent of metal to support interactions in these catalysts.

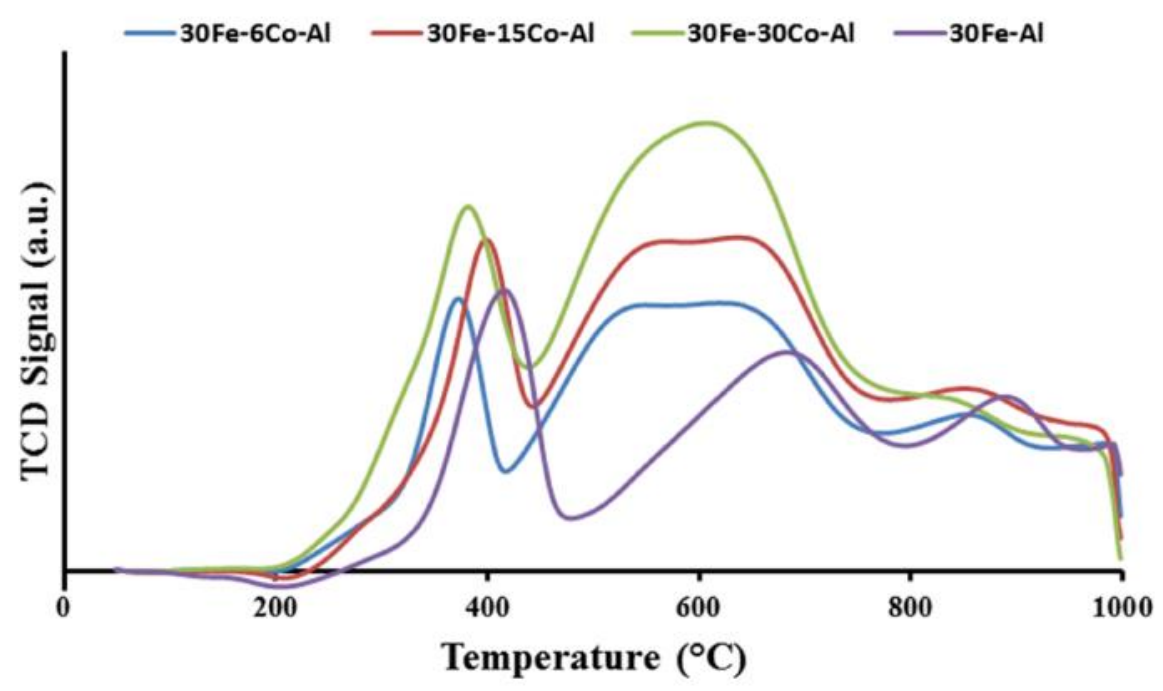

Fig.3 $\mathrm{H}_{2}$-TPR Patterns for Fresh 30 Fe-Al Catalysts Series for Different Cobalt Loadings. 
The results of $30 \% \mathrm{Fe} / \mathrm{Al}$ catalysts in terms of $\mathrm{CH}_{4}$ conversion of different Co loadings $(0 \%, 6 \%, 15 \%$ \& 30\%) were presented in Fig. 4. From the obtained results, it was apparent that the Co loading had fairly impact on their catalytic performance. It was obvious from Fig. 4 that the activity of $\mathrm{CH}_{4}$ increased with the increment in of the $\mathrm{Co}$ loading up to
$15 \%$. However, further increment in loading caused reduction in $\mathrm{CH}_{4}$ conversion. For instance, for $30 \%$ Co had shown $63.2 \%$ initial methane conversion; while, after three hours, the same catalyst had shown $70.6 \%$. The $15 \%$ Co catalyst has given better trends of $\mathrm{CH}_{4}$ activity, since it varied from $64.1 \%$ to $72.5 \%$ with the same time span.

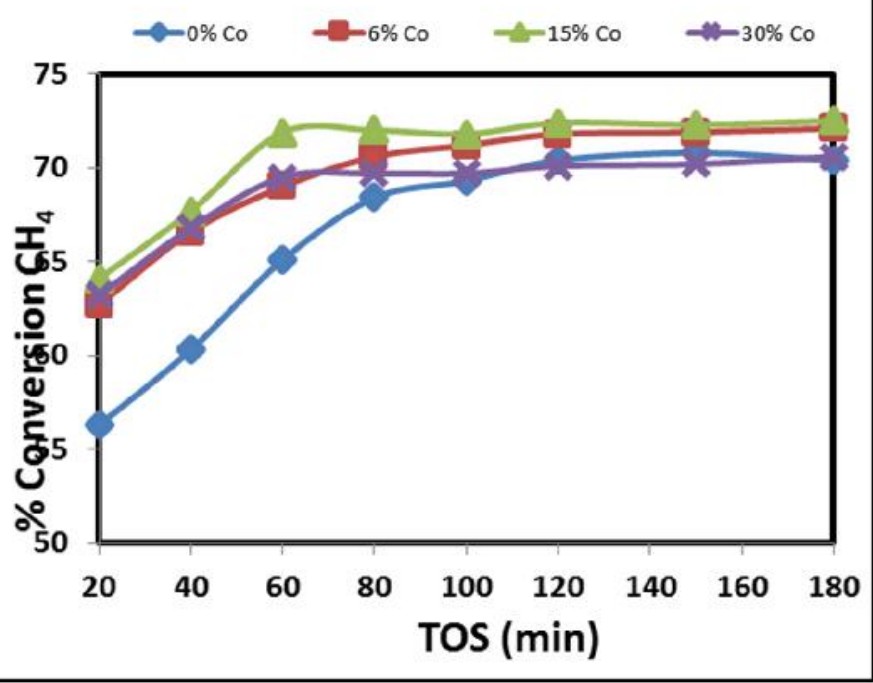

Fig.4 Variations of Hydrogen Conversion for Three Hours' Time on Stream of $30 \% \mathrm{Fe}-\mathrm{xCo} / \mathrm{Al}_{2} \mathrm{O}_{3}$ Catalyst Activated at $500{ }^{\circ} \mathrm{C}$

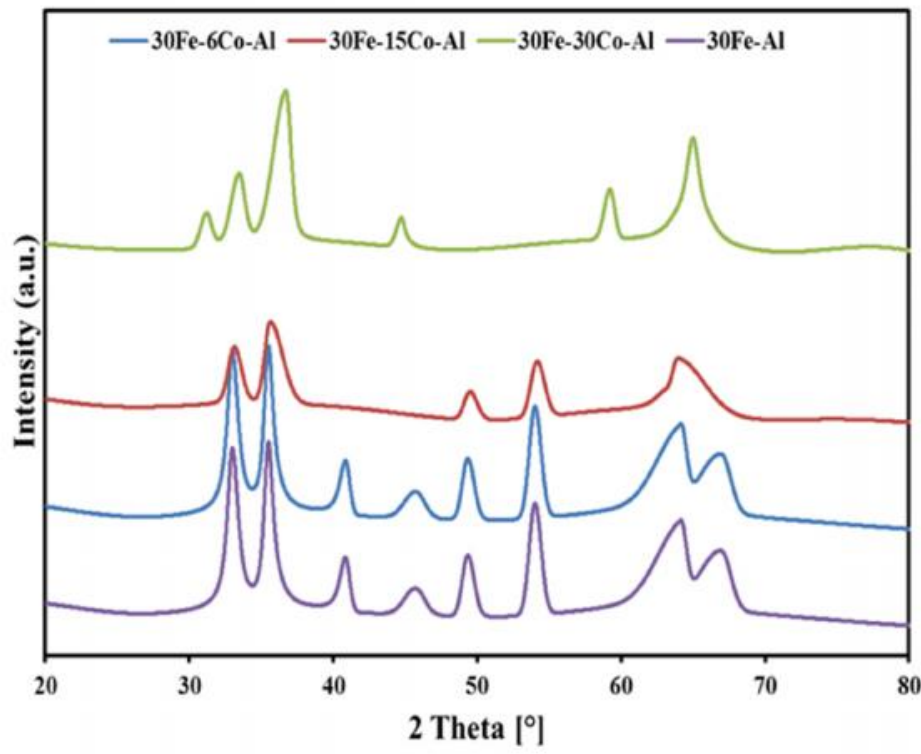

Fig. 5 XRD Patterns in 30Fe-Al Catalyst Series of Different Co Loadings

Figure 5 presented the XRD patterns in $30 \%$ Fe alumina supported catalyst series of different Co loadings. It is apparent from XRD diffractograms that the catalysts had shown crystallinity behavior, since obvious reflections were observed in XRD profiles. The intense diffraction lines were observed at $2 \theta=32.8^{\circ}, 35.4^{\circ}, 40.6^{\circ}, 49.1^{\circ}, 53.8^{\circ}, 63.7^{\circ}$ and
$2 \theta=66.1^{\circ}$, correspond to $\mathrm{Fe}_{2} \mathrm{O}_{3}$ hematite (JCPDS: 01-0840309). The coupling of $6 \%$ Co did not change the pattern at all while the higher loadings 15\% Co and 30\% Co had less number of peaks which modified the interaction between active metals and the support. This was also reflected in the enhancement of conversion for $15 \% \mathrm{Co}$. 


\section{Conclusion}

Catalytic thermal decomposition of methane to $\mathrm{COx}$-free hydrogen and carbon nanomaterials was studied over $30 \% \mathrm{Fe}$ catalysts supported on $/ \mathrm{Al}_{2} \mathrm{O}_{3}$. The effect of Co coupling with $30 \% \mathrm{Fe} / \mathrm{Al}$, ranging from 0 to $30 \%$ Co loading, over impregnated catalysts was investigated. The activity results revealed that the $15 \%$ Co loading was relatively better than other Co loadings. It was found that $15 \%$ Co catalyst has given better trends of $\mathrm{CH}_{4}$ activity. The methane conversion values varied from $64.1 \%$ to $72.5 \%$ during the three hours time on stream.

\section{Acknowledgements}

The authors thankfully acknowledge their appreciation to King Abdul-Aziz City for Science and Technology (KACST) for funding the work through the research project \# AT-34-4

\section{References}

[1] A.R. Gonza' lez, Y.J.O. Asencios, E.M. Assaf, J.M. Assaf, Dry reforming of methane on $\mathrm{Ni}-\mathrm{Mg}-\mathrm{Al}$ nanospheroid oxide catalysts prepared by the sol-gel method from hydrotalcite-like precursors, Appl. Surf. Sci. 280 (2013) 876-887.

[2] L. Xu, H. Zhao, H. Song, L. Chou, Ordered mesoporous alumina supported nickel based catalysts for carbon dioxide reforming of methane, Int. J. Hydrogen Energy 37 (2012) 7497-7511.

[3] N. Sun, X. Wen, F. Wang, W. Peng, N. Zhao, F. Xiao, W. Wei, Y. Sun, J. Kang, Catalytic performance and characterization of $\mathrm{Ni}-\mathrm{CaO}-\mathrm{ZrO}_{2}$ catalysts for dry reforming of methaneAppl. Surf. Sci. 257 (2011) 9169-9176.

[4] R. Shang, X. Guo, S. Mu, Y. Wang, G. Jin, H Kosslick, A. Schulz, X.-Y. Guo, Carbon dioxide reforming of methane to synthesis gas over $\mathrm{Ni} / \mathrm{Si} 3 \mathrm{~N} 4$ catalysts, Int. J. Hydrogen Energy 36 (2011) 49004907.

[5] F. Meshkani, M. Rezaei, Nanocrystalline $\mathrm{MgO}$ supported nickel-based bimetallic catalysts for carbon dioxide reforming of methane, Int. J. Hydrogen Energy 35 (2010) 10295-10301.

[6] E. Kirtay, Recent advances in production of hydrogen from biomass, Energy Convers. Manage. 52 (2011) 1778-1789.

[7] M. Ni, M.K.H. Leung, D.Y.C. Leung, K. Sumathy, A review and recent developments in photocatalytic water-splitting using for hydrogen production, Renewable Sustainable Energy Rev. 11 (2007) 401425 .
[8] H.Z. Wang, D.Y.C. Leung, M.K.H. Leung, M. Ni, A review on hydrogen production using aluminum and aluminum alloys, Renewable Sustainable Energy Rev. 13 (2009) 845-853.

[9] Ibrahim AA, Fakeeha AH, Al-Fatesh AS. Enhancing hydrogen production by dry reforming process with strontium promoter. Int $\mathrm{J}$ Hydrogen Energy 39(2014)1680-1687.

[10] J. Ashok, M. Subrahmanyam, A. Venugopal, Development of methane decomposition catalysts for COx free hydrogen, Catal. Surv. Asia 12 (2008) 229237.

[11] Prabhas Jana, Víctor A. de la Peña O`Shea, Juan M. Coronado, David P. Serrano, $\mathrm{H}_{2}$ production by $\mathrm{CH}_{4}$ decomposition over metallic cobalt nanoparticles: Effect of the catalyst activation, Applied Catalysis A: General 467 ( 2013 371-379

[12] Manoj Pudukudy, Zahira Yaakob, Mohd Sobri Takriff, Methane decomposition over Pd promoted $\mathrm{Ni} / \mathrm{MgAl} 2 \mathrm{O} 4$ catalysts for the production of $\mathrm{COx}$ free hydrogen and multiwalled carbon nanotubes, Applied Surface Science 356(2015) 1320-1326

[13] K. Otsuka, S. Kobayashi, S. Takenaka, HydrogenDeuterium Exchange Studies on the Decomposition of Methane over Ni/SiO 2 , J. Catal. 200 (2001) 4-9

[14] Gac, W., A. Denis, T. Borowiecki and L. Kepinski; "Methane decomposition over $\mathrm{Ni}-\mathrm{MgO}-\mathrm{Al}_{2} \mathrm{O}_{3}$ catalysts," Applied Catalysis A: General, 357, (2009)236-243

[15] Ahmed A. Ibrahim, Anis H. Fakeeha, Ahmed S. AlFatesh, Ahmed E. Abasaeed, Wasim U. Khan, Methane decomposition over iron catalyst for hydrogen production, , Int. J. Hydrogen Energy 40 (2015 ) $7593-7600$.

[ 16] Jana, P., V.A. de la Peña O'Shea, J.M. Coronado and D.P. Serrano; "Cobalt based catalysts prepared by the Pechini method for $\mathrm{CO}_{2}$-free hydrogen production by methane decomposition," International Journal of Hydrogen Energy 35 (2010)10285-10294.

[17] Lamouroux, E., P. Serp and P. Kalck; "Catalytic routes towards single wall carbon nanotubes," Catalysis Reviews: Science and Engineering 49(2007) 341-405.

[18] Jozwiak, W. K., E. Kaczmarek, T.P. Maniecki, W. Ignaczak and W. Maniukiewicz; "Reduction behavior of iron oxides in hydrogen and carbon monoxide atmosphere,". Applied Catalysis A: General 326(2007) 17-27. 